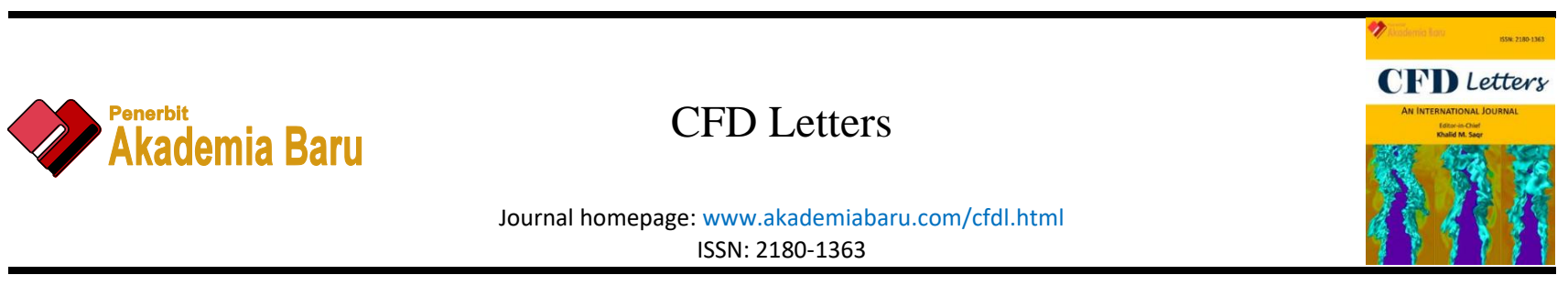

\title{
Effect of Different Orifice Diameter on The Flow Characteristic in Pressurized Metered Dose Inhaler by Using CFD
}

\author{
Muhammad Faqhrurrazi Abd Rahman ${ }^{1,}{ }^{*}$, Norzelawati Asmuin ${ }^{1}$, Nurul Fitriah Nasir ${ }^{1}$, Ishkrizat Taib ${ }^{1}$, \\ Mohamad Nur Hidayat Mat ${ }^{1}$, Riyadhthusollehan Khairulfuaad ${ }^{1}$ \\ 1 Department of Thermofluids Engineering, Faculty of Mechanical and Manufacturing Engineering, Universiti Tun Hussein Onn, 86400 Parit Raja, \\ Johor, Malaysia
}

ARTICLE INFO

\section{Article history:}

Received 22 January 2020

Received in revised form 17 March 2020

Accepted 22 March 2020

Available online 28 March 2020

\section{Keywords:}

Alveoli; orifice; pressurized metered dose inhalers; simulation

\section{ABSTRACT}

\begin{abstract}
Pressurized metered dose inhalers (pMDI) are portable, easy to use, convenient and these devices used multi-dose to administer aerosolized drug that use a propellant. A dose of medication actually is fixed and can be delivered with each actuation. There is a problem for this pMDI inhaler devices which is the particle do not reach into the alveolar. ANSYS Fluent Version 19.2 was used for parametric analysis to find the best orifice diameter. Standard K-epsilon was used as the turbulence model with enhanced wall treatment function. Discrete phase model was applied to represent the particle flow. The result shows that the best orifice diameter is $0.39 \mathrm{~mm}$ that affect the highest particle velocity magnitude.
\end{abstract}

Copyright @ 2020 PENERBIT AKADEMIA BARU - All rights reserved

\section{Introduction}

Pressurized metered dose inhalers (pMDI) are portable, easy to use, convenient and this device used multi-dose to administer aerosolized drug that use a propellant. A dose of medication actually is fixed and can be delivered with each actuation [1]. There are three (3) types of inhaler devices such as nebulizers, dry powder inhalers and pressurized dose inhalers (pMDI). This device usually can produce fine drug particles and inhaled orally aiming the deep lung deposition [2]. Among these devices, $\mathrm{pMDI}$ is one of the favorite devices that being selected for treatment asthma and chronic obstructive pulmonary disease (COPD) patients [3]. In 1998, the pMDI inhaler is rising from 440 million unit to 800 million units in 2000 and represent more than $80 \%$ of the medicine therapy devices marketed worldwide in 2004 [4]. Chlorofluorocarbons (CFC) was used in the past in the propellant, but, the United Nations already banned this gaseous due to their harmful effects on the ozone layer [5]. In compliance with Montreal Protocol of 1987 [6], Hydrofluoroalkane propellants (HFA) been used because do not have ozone depleting properties and Chlorofluorocarbons propellants are being replace [7]. The previous researcher Cheng et al., calculated the drug delivery efficiency of CFC-pMDI

\footnotetext{
* Corresponding author.

E-mail address: hd170038@siswa.uthm.edu.my (Muhammad Faqhrurrazi Abd Rahman)
} 
and HFA-pMDI in a human airways respiratory replica. The study involves the oropharyngeal cavity, larynx, trachea and nice of the bronchus generation. The value of the mass median aerodynamic diameter (MMAD) and geometric standard deviation for CFC-pMDI and HFA-pMDI were $2.33 \mu \mathrm{m}(\sigma \mathrm{g}$ $=1.79)$ and $2.21 \mu \mathrm{m}(\sigma g=1.76)$ respectively. The results presented that when the inhalation flow rate is $30 \mathrm{~L} / \mathrm{min}$, the CFC-pMDI can generate $78 \%$ deposition in the oropharyngeal airway and $16 \%$ deposition in the lung while the HFA-pMDI can generate less deposition in the oropharyngeal airway by $56 \%$ but can increased the deposition in lung by $24 \%$ [8]. Drug formulation that stored in the device incorporates a disposable canister can be replaced for a new one at any time [9]. In pMDI inhaler device, there are four type of the components that can be found, the metering valve, the formulation canister, the container and the container. pMDI schematic cross-section are shown in Figure 1 [10]. The size of the particle aerosol can be produced by a pMDI depends on the ambient temperature, valve design, pressure of the propellant mixture, drug concentration and actuator orifice. In fact, the particle size distribution and the actuator nozzle diameter have a relationship between them [11].

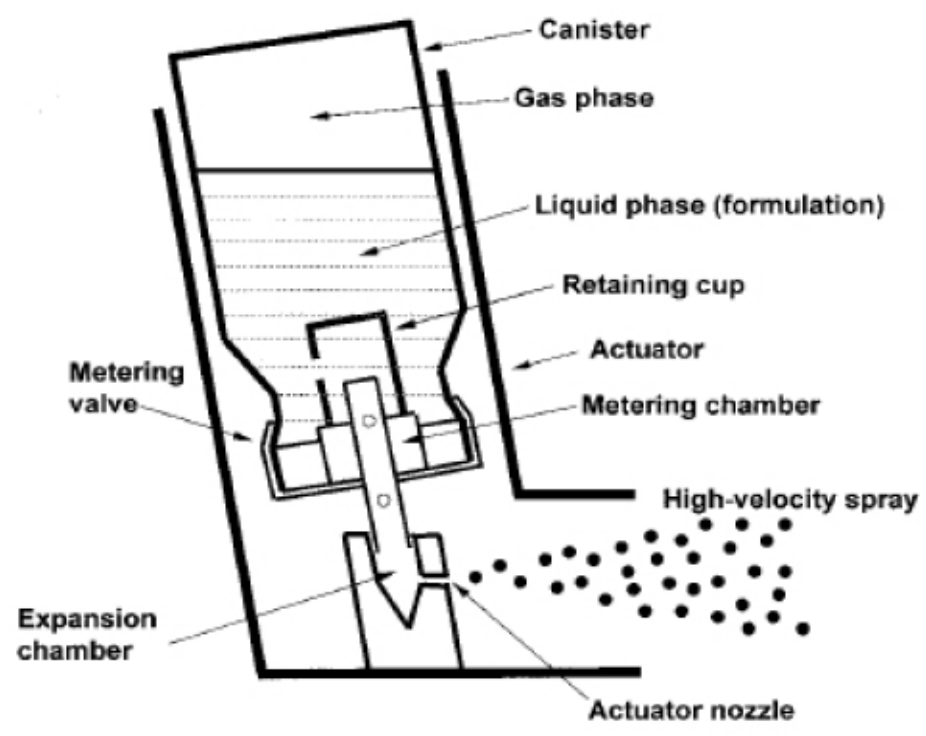

Fig. 1. pMDI schematic cross-section [10]

When the formulation expands from the confinement of the metering chamber, the atomization process was beginning, the vapour cavitation was forming within the regions of the valve stem, actuator sump and over the length of the actuator orifice $[12,13]$. In period of $0.1 \mathrm{~s}-0.5 \mathrm{~s}$, the atomization event typically occurs and possible to extends within 2-3s with a good combination range of deep, slow and inhalation by decreasing the actuator orifice diameter or growing its length [14]. The evidently shows that increasing pressure difference can decreased the particle sized diameter [15]. The plume duration from $0.5 \mathrm{~s}$ can be doubled to $1.2 \mathrm{~s}$ by reducing the diameter of the orifice from 0.22 to $0.14 \mathrm{~mm}$ and the mean ex-valve respirable can be increased from 48 to $79 \%$ [16]. Higher flow rate increases liquid swirling strength, increase air core diameter which decreases the liquid film thickness in the swirl chamber and discharge orifice [17]. The highest ex-valve fine particle fractions can be achieved with the smaller actuators orifice diameter, smaller metering volumes and high propellant contents. The respirable drug mass can be raised by decreasing the orifice length and/or the orifice cross-sectional area [18].

The supplied temperature of cloud to the patient can be increased by adding co-solvents which is ethanol, to prevent the evaporation rate, the unit of dose metering volume can be decreased by increasing the drug concentration, actuator orifice diameter can be reduced or the length of the 
actuator can be slightly increased $[19,20]$. In this project, there has been none researcher investigating the effect of actuator nozzle angle on its performance in terms of particle velocity magnitude. Therefore, this research aiming to analyze different parametric design for actuator nozzle aligned with the objective of this research.

\section{Methodology}

\subsection{Geometrical Modelling}

The Solidwork 2016 was used to design the three-dimensional model of pMDI inhaler device are shown in Figure 2(a) while the schematic of an internal parts in the actuator nozzle is presented in Figure 2(b) Geometrical representation pMDI Inhaler dimension was referred from previous literature on the pMDI Sprays: Theory, Experiment and Numerical Simulation [21]. Based on their simulation results done by Ricardo F. Oliveira et al., [21], it was found that the based design result for diameter of the orifice is $0.49 \mathrm{~mm}$, the angle of the orifice is $165^{\circ}$ and the length of the orifice is $1.50 \mathrm{~mm}$ are respectively. The internal parts in the actuator nozzle was taken for simulation analysis on different parameter as shown in Figure 2(b). A parameter was used to define the geometry of the actuator nozzle was orifice diameter (D).

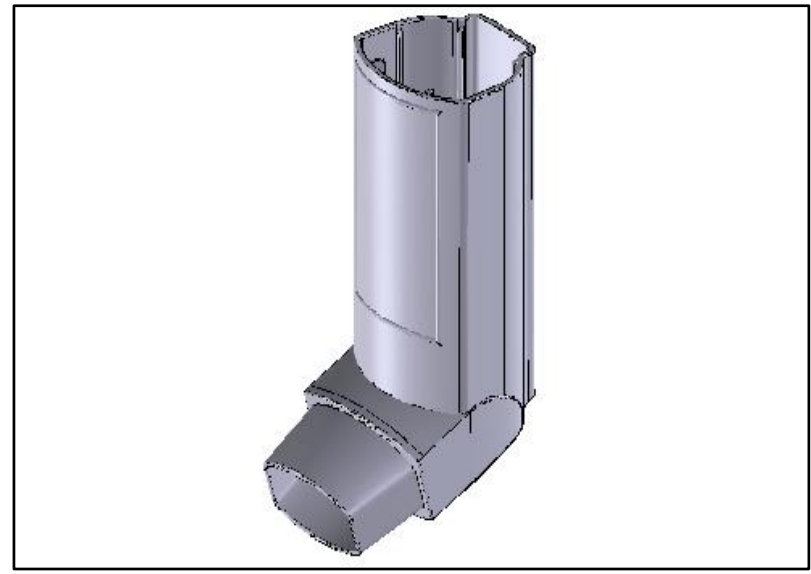

(a)

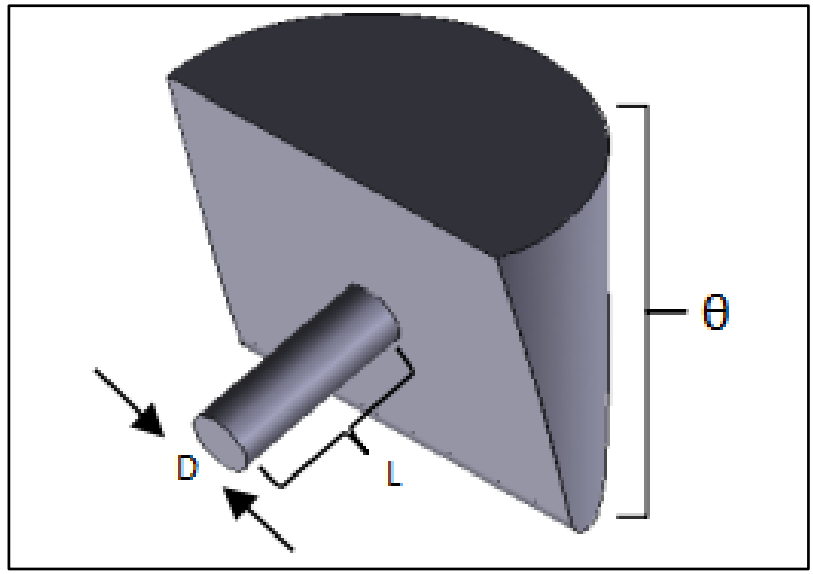

(b)

Fig. 2. Geometrical modelling of pMDI inhaler device (a) 3D design of pMDI inhaler using Solidwork 2016,

(b) Schematic diagram of internal parts in the actuator nozzle

\subsection{Meshing for pMDI Inhaler Device Geometry}

The below dimension meshed model that be designed in mesh mode of ANSYS components systems are shown in Figure 3 . The infinite number of the particles can be converting into finite number of particles in the meshing mode. The compulsory in meshing cell has to be done in high efficiency and precision. The refine (use in smaller cells) mesh can be setup for a big solution gradients and fine geometrical details but, for the coarse mesh (use in giant cells) could be elsewhere. It is necessary for the solution to maintain the accuracy and stability in order to get a good quality of the mesh. In the ANSYS, there are four operation mesh mode can be done. The process was beginning with specifying the global mesh setting, inserting a local mesh setting, generating the mesh and checking mesh quality. The curve object (cylinder) and square object (box) can be selected as the convergent section by using the proximity and curvature. The Grid Independent Test was needed to selected the meshing size. 


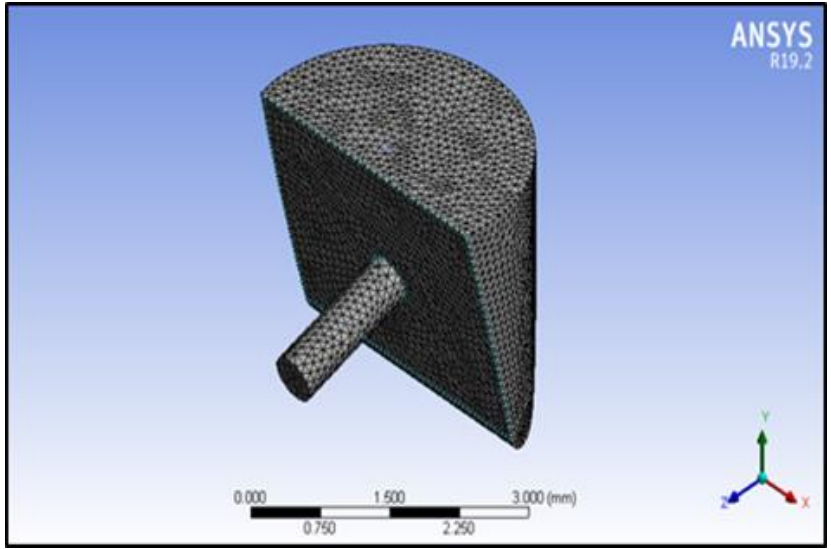

(a)

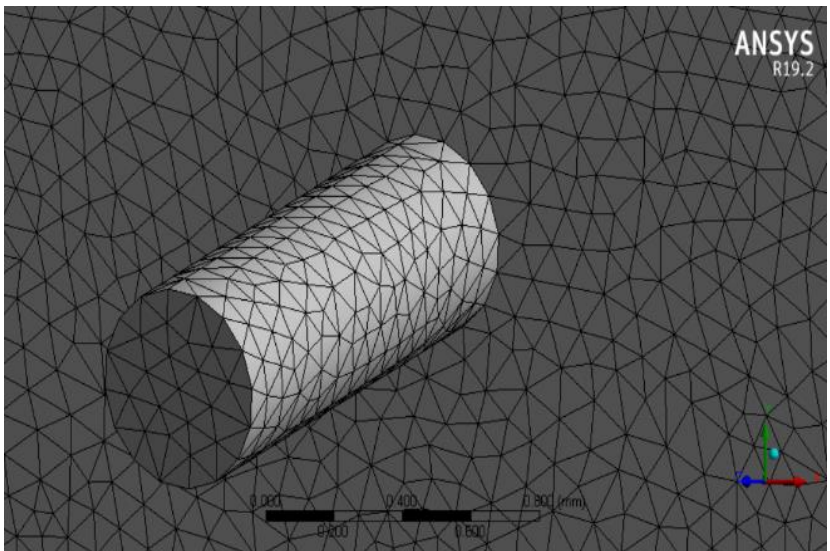

(b)

Fig. 3. Meshing process for internal parts in the actuator nozzle (a) Meshed model of the nozzle (b) Details view for the orifice diameter in the actuator nozzle

\subsection{Grid Independent Test}

A pMDI inhaler model devices was redesigned from the previous literature study on pMDI Sprays: Theory, Experiment and Numerical Simulation [21]. The precision of the model can be maintaining by using the Grid-independent test and it is compulsory. The Grid-independent test value must keep low as possible to maintain their accuracy. However, the coarse, medium and fines meshed can be created in this GID sequence and it can shows that the solution can change between medium and fine mesh. Grid independent test for based model are shown in Table 1. There are eight tests for the GID has been done. The best GID can be choose based on the lower the value for the skewness mesh metric and the highest the orthogonal mesh metric. From this table, it shows that number five fulfill the selection of criteria. GID already done by choosing the number five for further simulation analysis.

Table 1

Grid independent test for based model

\begin{tabular}{lllll}
\hline No & Number of Nodes & Number of Elements & Skewness Mesh Metric & Orthogonal Mesh Metric \\
\hline 1 & 246636 & 573738 & 0.24551 & 0.75306 \\
2 & 155176 & 420206 & 0.41719 & 0.58143 \\
3 & 214422 & 570163 & 0.25601 & 0.7426 \\
4 & 242386 & 472759 & 0.24405 & 0.75445 \\
5 & 262512 & 572801 & 0.24172 & 0.75681 \\
6 & 118616 & 372876 & 0.40953 & 0.58891 \\
7 & 115079 & 364531 & 0.41719 & 0.58143 \\
8 & 214246 & 433875 & 0.25473 & 0.74563 \\
\hline
\end{tabular}

The main properties of drug formulation for propellant-HFA 134a, Ethanol and Salbutamol involved in this study a listed in Table 2:

Table 2

Property of drug formulation [25]

\begin{tabular}{llll}
\hline Properties & HFA-134a & Ethanol & Salbutamol \\
\hline Density $\left(\mathrm{kg} / \mathrm{m}^{3}\right)$ & 1311 & 790 & 1230 \\
Specific Heat $(\mathrm{j} / \mathrm{kg}-\mathrm{k})$ & 982 & 2470 & - \\
Thermal Conductivity $(\mathrm{w} / \mathrm{m}-\mathrm{k})$ & 0.0857 & 0.182 & - \\
Viscosity $(\mathrm{kg} / \mathrm{m}-\mathrm{s})$ & 0.000211 & 0.0012 & - \\
Molecular Weight $(\mathrm{kg} / \mathrm{kmol})$ & 102.032 & 46.07 & 337.387 \\
\hline
\end{tabular}




\subsection{CFD Simulation Method}

The present simulation aims to highlight the configuration parameters that better fits the reallife case of a pMDI inhaler spray, by using commercially available CFD software, such as Fluent version 19.2 from ANSYS $^{\circledR}$. In the Discrete phase model, Rosin-Rammler has been chosen as diameter distribution. The CFD solver accepts this distribution type by inserting its corresponding parameters shown in Table 3 [22].

Table 3
Particles diameter distribution

In this spray parameters used to configure the solver; the angle was obtained by the high-speed image. The drug amount of puff $(100 \mu \mathrm{g})$ can be used and divided by the duration of a puff $(0.1 \mathrm{~s})$. The spray flow rate can be possible to calculate by using the amount of puff and duration of puff. The solver spray configuration parameters are shown in Table 4 below.

Table 4

Solver spray configuration parameters

\begin{tabular}{ll}
\hline Parameter & Value \\
\hline Spray type & Solid-cone $[9,18]$ \\
Angle $\left(^{\circ}\right)$ & $10[21]$ \\
Velocity $(\mathrm{m} / \mathrm{s})$ & $100[23]$ \\
Radius $(\mathrm{m})$ & $0.00025[9,19]$ \\
Flow rate $(\mathrm{kg} / \mathrm{s})$ & $1 \mathrm{e}^{-6}[21]$ \\
\hline
\end{tabular}

Parameters for the discrete phase model already been tested with different configuration and the ones presented here seemed to be most suitable to use in simulation. The inject time step size (s) use for this DPM are particle time step. Limited period time $(0.1 \mathrm{~s})$ for injection occurs, the unsteady particle tracking was used. The spherical type was used as the drag law and the two-way coupling turbulence is activated for this simulation [21].

\subsection{Model Verification}

The verification of the $\mathrm{pMDI}$ inhaler devices was done by comparing the highest maximum particle velocity magnitude, velocity magnitude, air temperature and HFA mass from the previous literature study as presented in Table 5. The reference model for verification was based on the pMDI Sprays: Theory, Experiment and Numerical Simulation [21]. The previous model was simulated by using the Ansys Fluent version 14.0. On the other hand, this study would do the simulation by using Ansys Fluent version 19.2. The maximum relative error shown in the table below for the geometrical modelling is $6.2 \%$. Accordance to Goswami, Kumar and Munshi 2015, for the numerical simulation, the average limit for comparing two (2) simulated model is below $10 \%$ [24]. The further simulation can be proceeding because the maximum value is below that average limit and the geometrical simulation is acceptable. 


\section{Table 5}

Verification of based model geometry

\begin{tabular}{lllll}
\hline $\begin{array}{l}\text { Velocity } \\
\text { Inlet }(\mathrm{m} / \mathrm{s})\end{array}$ & Variable Parameters & Result by Fluent & Result by Fluent & Relative Error (\%) \\
\hline 100 & & 14.0 & 19.2 & \\
& Particle Velocity Magnitude $(\mathrm{m} / \mathrm{s})$ & 29.298 & 28.421 & 3.6 \\
& Velocity Magnitude $(\mathrm{m} / \mathrm{s})$ & 10.29 & 10.91 & 6.0 \\
& Air Temperature $(\mathrm{K})$ & 293.15 & 293.01 & 0.05 \\
& HFA Mass Fraction & 0.0029 & 0.0027 & 6.2 \\
\hline
\end{tabular}

\section{Results}

\subsection{Qualitative Analysis of Flow characteristic of Actuator Nozzle Along the Axis of Centerline}

The axis of centerline inside nozzle cavity is presented in Figure 4 while the flow characteristic in term of pressure, velocity, eddy viscosity, turbulent eddy dissipation, turbulent kinetic energy and particle mass concentration development along the nozzle centerline are presented in Figure 5 . The particle mass concentration against average position along the axis of centerline is presented in Figure 5(a). Particle mass concentration represents the drug distribution along the orifice centerline. The measurement was taken from orifice inlet to outlet that represent the axis of centerline. The result shows that the pattern of the graph increased on the particle mass concentration inside the actuator nozzle cavity with the position along the centerline. Another significant result shows that the orifice diameter of $0.41 \mathrm{~mm}$ give the lowest value of particle mass concentration along the axis of the centerline from the rest. The increasing of particle mass concentration is due to collision between particles along axis of centerline. The eddy dissipation and versus position along the axis of centerline was display in Figure 5(b). The overall trends for this eddy dissipation increased with the increment of the position along the orifice centerline as presented as shown in Figure 5(b). The result shows as the significant findings for orifice diameter, $0.39 \mathrm{~mm}$ when give the highest value of eddy viscosity from the rest. The highest value of $0.39 \mathrm{~mm}$ orifice diameter for eddy viscosity is due to the highest particle flow development inside orifice cavity as presented in Figure 5(e). The graph in Figure 5(c) displays the result of pressure against average position along the axis of centerline. The pressure of particles represents the drug distribution along the orifice centerline. The result displays the pattern of the graph slowly decreased before the position of $-0.00008 \mathrm{~m}$ and steeply decreased after that. In fact, the finding shows the orifice diameter of $0.39 \mathrm{~mm}$ and $0.59 \mathrm{~mm}$ give the lowest and the highest value of pressure respectively. The trend was similarly observed in the experiment conducted by Stein where increasing the cross-sectional area increased the particles distribution. It shows that the bigger cross-sectional area, the particles exert more pressure compared to smaller area [22]. The turbulence eddy dissipation and versus position along the axis of centerline was display in Figure 5(d). The graph shows the increasing in trend before the position of $-0.00155 \mathrm{~m}$ and start decreasing after the point. Reducing the orifice diameter increased the turbulence eddy dissipation as shown in the graph where the orifice with the smallest tested diameter $(0.39 \mathrm{~mm})$ had the highest value of turbulence eddy dissipation. According to continuity equation, reducing the value of cross-sectional area responsible for increasing the value of flow velocity. Thus, in this case, the lowest orifice diameter generated highest particles velocity. This result in development of turbulence flow which is turbulence eddy dissipation. Turbulence kinetic energy against position along the axis of centerline is presented in Figure 5(e). Generally, the turbulence kinetic energy trend starts to increase in the range between -0.00016 to -0.00008 and decline afterward. The turbulence kinetic energy can be increased by decreasing the diameter of the orifice from $0.59 \mathrm{~mm}$ to $0.39 \mathrm{~mm}$. By referring to graph in Figure 5(b), particle mass concentration increased with increment of the position. Thus, this cause more particle collisions to each other and subsequently create turbulence kinetic energy. The graph 
in Figure 5(f) displays the result of velocity against position along the axis of centerline. The velocity shows increasing in trends against position ranging from -0.00016 to -0.00008 and decline after that range. Another significant result shows that the gradient of orifice diameter $0.39 \mathrm{~mm}$ increased sharply along the axis of the centerline from the rest. Accordance to Bernoulli's principle, increasing the velocity will cause decreasing in pressure. Therefore, the smallest cross-sectional a rea will give highest velocity and reducing its pressure.

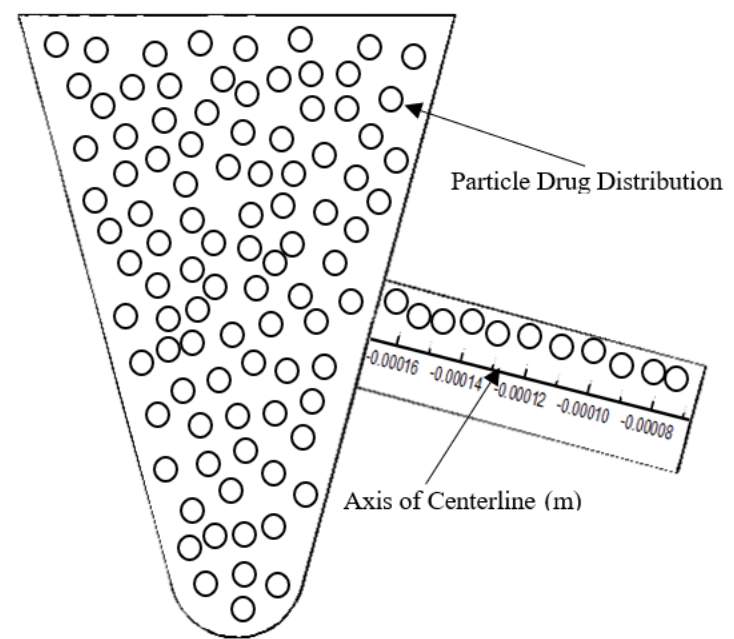

Fig. 4. Axis of centerline inside the actuator nozzle

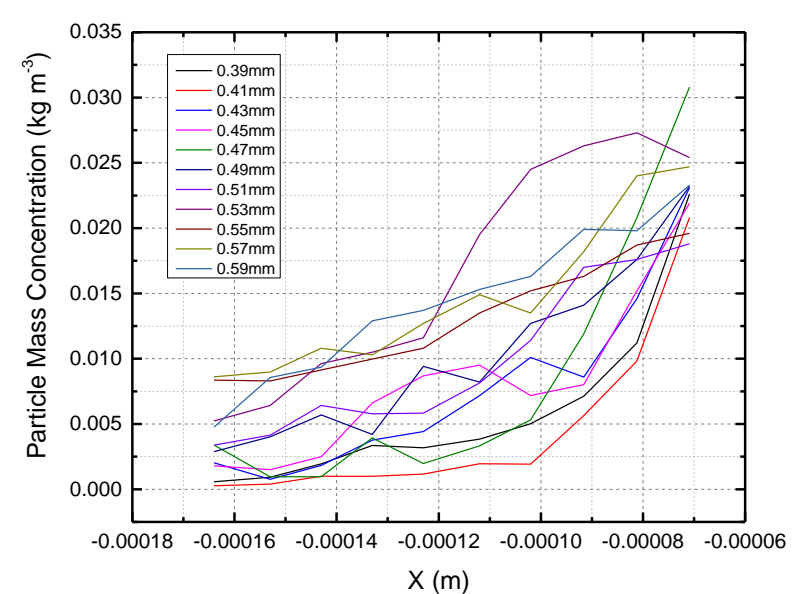

(a)

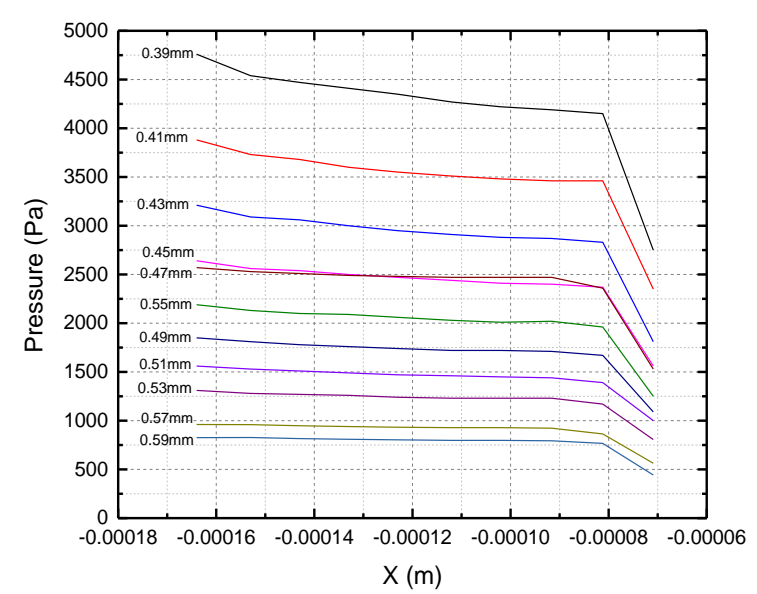

(c)

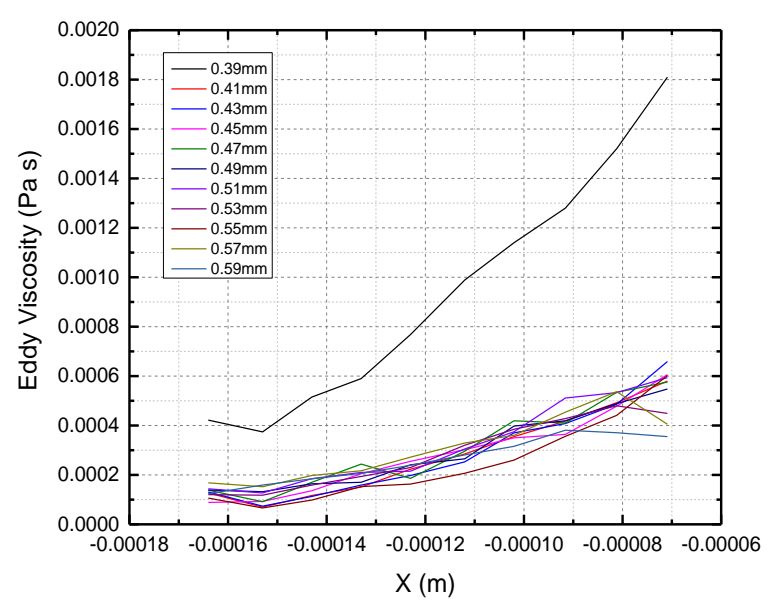

(b)

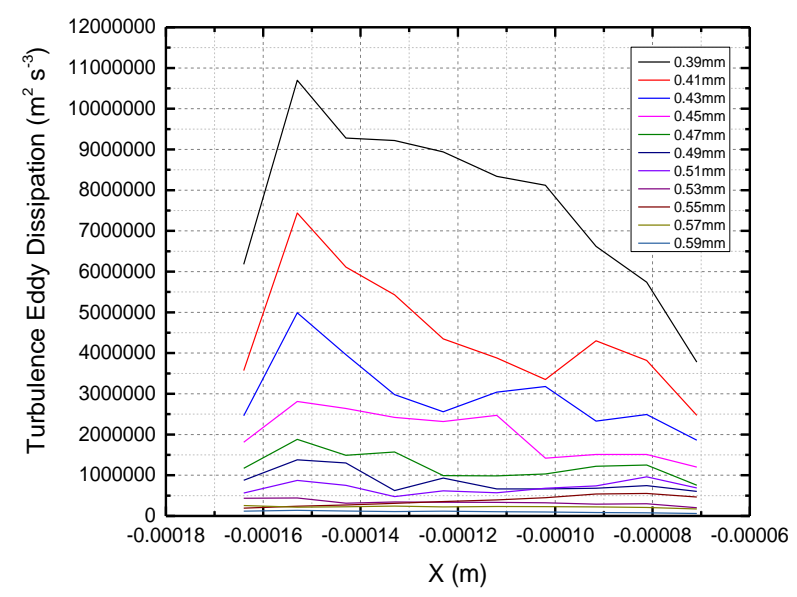

(d) 


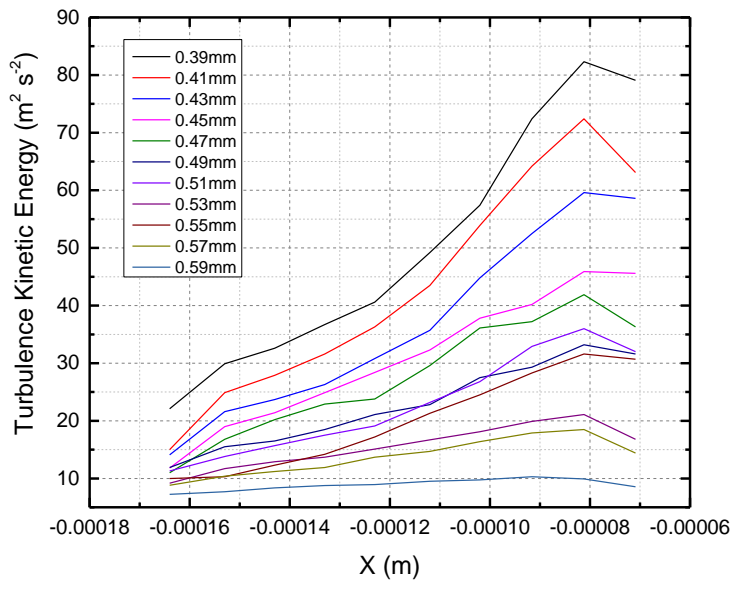

(e)

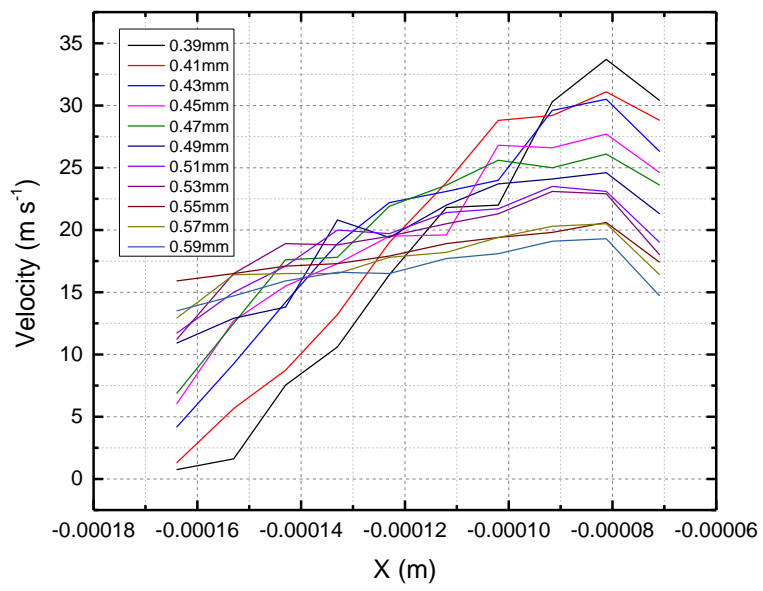

(f)

Fig. 5. Flow characteristic of Actuator Nozzle along Axis of Centerline (a) Particle mass concentration along the centerline (b) Eddy Viscosity (c) Pressure (d) Turbulence Eddy Dissipation (e) Turbulence Kinetic Energy (f) Velocity

\subsection{Qualitative Analysis of Particle Velocity Magnitude on Actuator Nozzle}

The particle velocity magnitude on different orifice diameter inside the actuator nozzle is shown in Figure 6. The simulation on the particle velocity magnitude is one of the critical parameters to recognize the flow inside the actuator nozzle. The result shows that the smallest cross-sectional area can produce highest velocity magnitude and more particle can be generated from the actuator nozzle. The $0.39 \mathrm{~mm}$ diameter of the orifice as shown in Figure $6(\mathrm{a})$ has the highest velocity while the lowest velocity of orifice diameter is $0.59 \mathrm{~mm}$ as shown in Figure $6(\mathrm{k})$. These values can be seen in color contour legend.
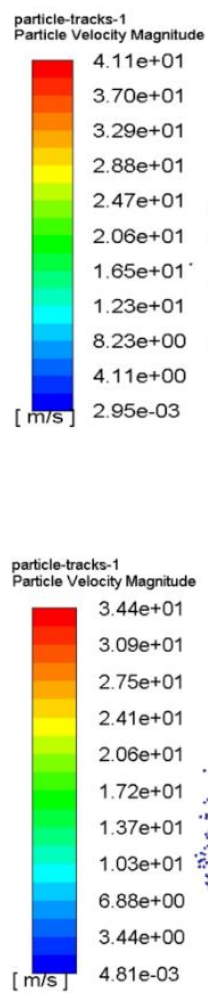

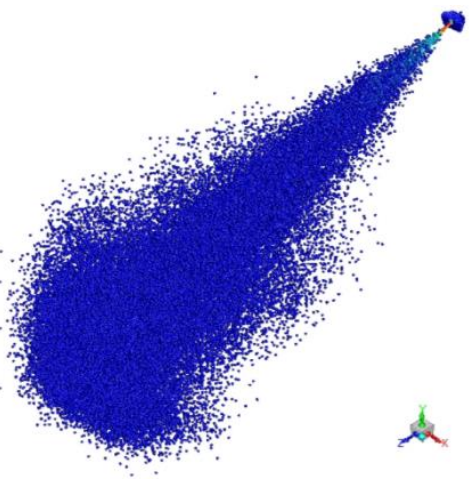

(a)

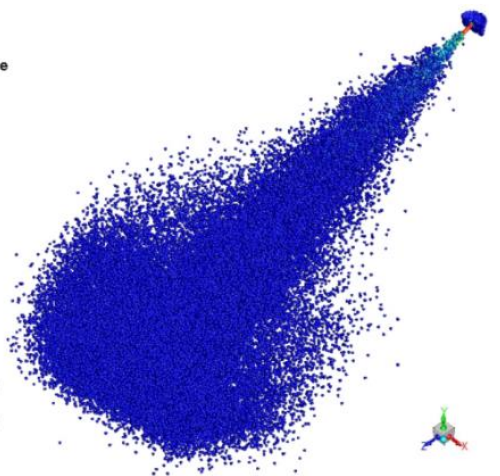

(c)
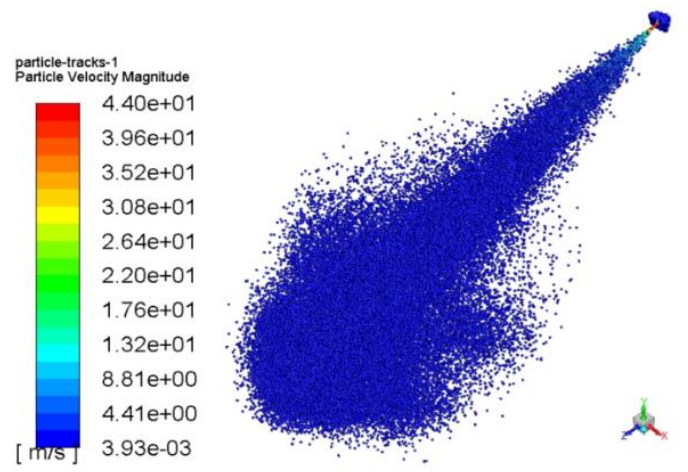

(b)
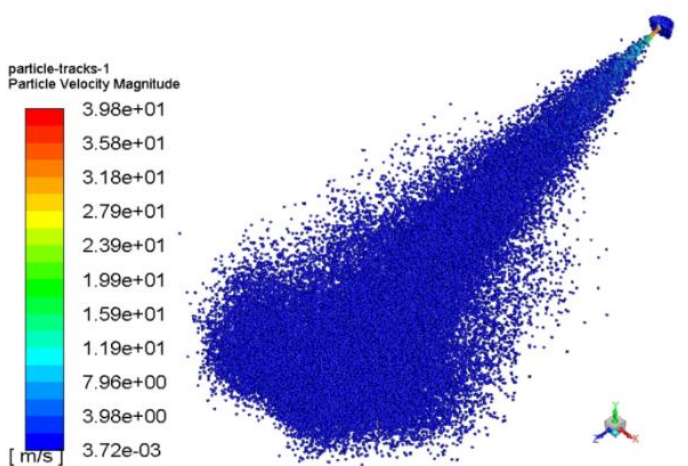

(d) 


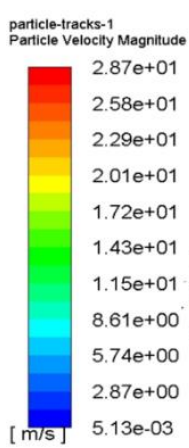

$5.13 e-03$

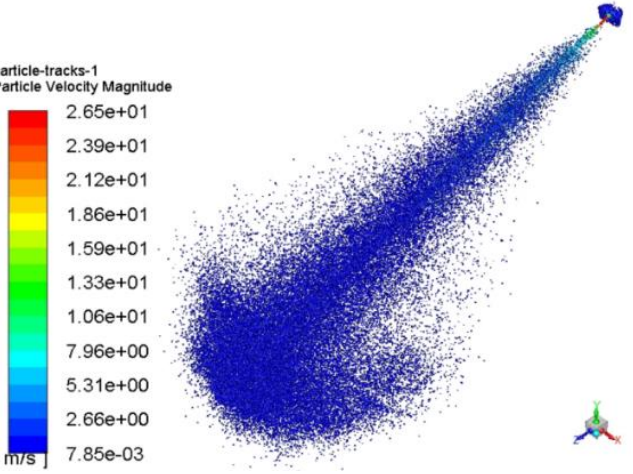

(g)
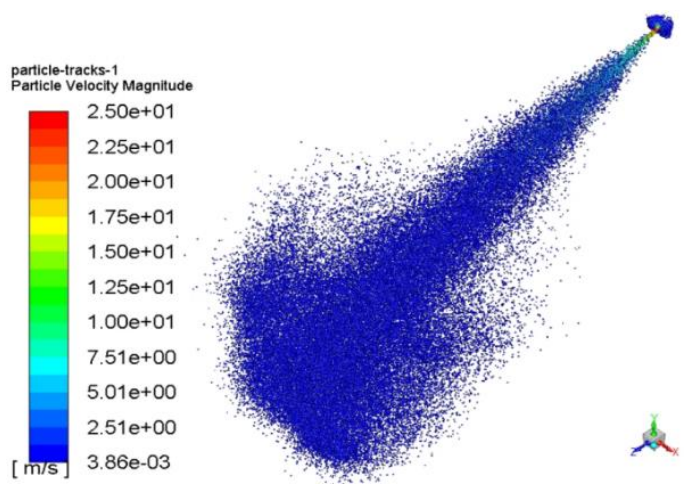

(i)

(e)
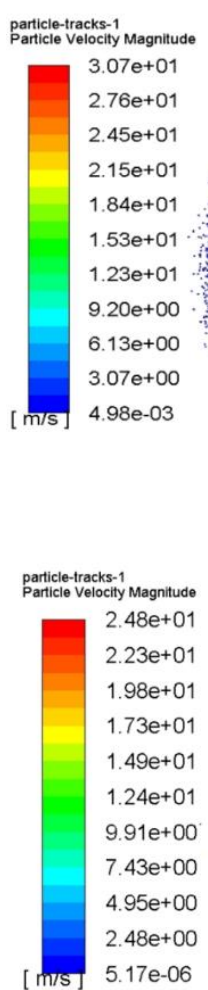

$17 e-06$

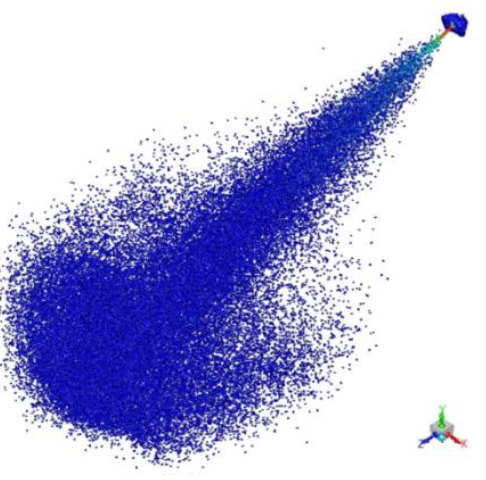

(f)

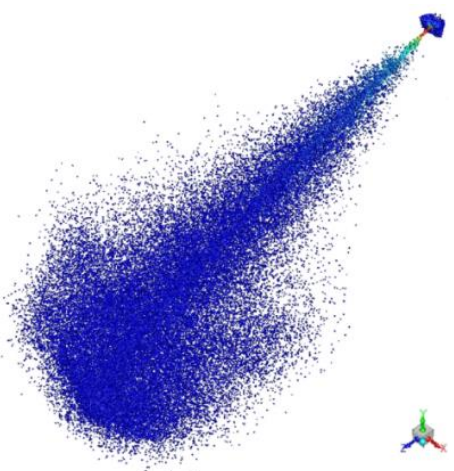

(h)
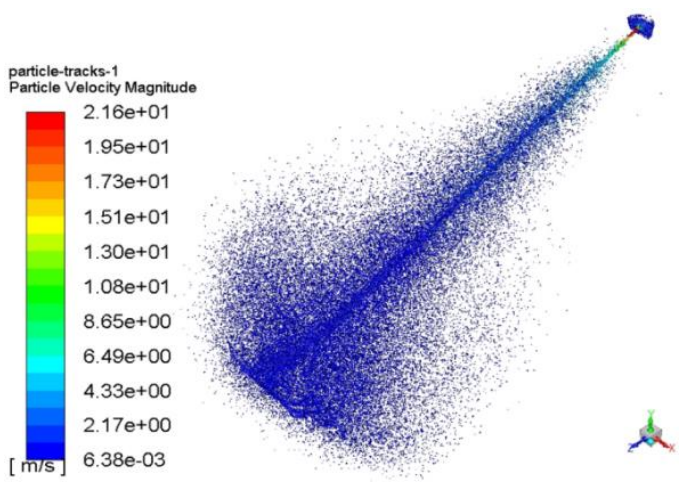

(j)
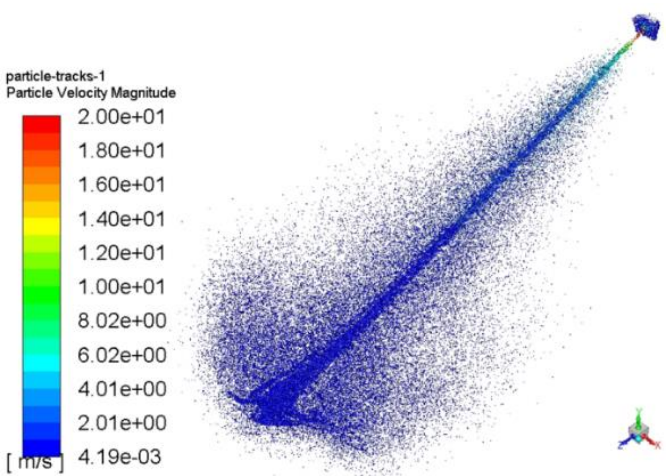

(k)

Fig. 6. Particle velocity magnitude on different orifice diameter inside the actuator nozzle; (a) $0.39 \mathrm{~mm}$ orifice diameter, (b) $0.41 \mathrm{~mm}$ orifice diameter, (c) $0.43 \mathrm{~mm}$ orifice diameter, (d) $0.45 \mathrm{~mm}$ orifice diameter, (e) $0.47 \mathrm{~mm}$ orifice diameter, (f) $0.49 \mathrm{~mm}$ orifice diameter, (g) $0.51 \mathrm{~mm}$ orifice diameter, (h) $0.53 \mathrm{~mm}$ orifice diameter, (i) $0.55 \mathrm{~mm}$ orifice diameter, (j) $0.57 \mathrm{~mm}$ orifice diameter, (k) $0.59 \mathrm{~mm}$ orifice diameter 


\section{Conclusions}

The particle flow characteristic by the flow in the actuator nozzle was analyzed by using the standard wall K-epsilon function and Discrete phase model mode. In the current study, a 3-D simulation has been carried out for eleventh (11) different diameter of the orifice. After run a few parametric analyses, it was discovered that $0.39 \mathrm{~mm}$ was provide the highest particle velocity magnitude compared to other data which were $0.41 \mathrm{~mm}, 0.43 \mathrm{~mm}, 0.45 \mathrm{~mm}, 0.47 \mathrm{~mm}, 0.49 \mathrm{~mm}$, $0.51 \mathrm{~mm}, 0.53 \mathrm{~mm}, 0.55 \mathrm{~mm}, 0.57 \mathrm{~mm}$ and $0.59 \mathrm{~mm}$. The result shows that, the $0.39 \mathrm{~mm}$ can gives the highest turbulence kinetic energy that resulted in the lowest pressure and the highest velocity development along the actuator orifice cavity as presented in section 3.1. The highest particle velocity magnitude can possibly make the drug reach the alveolar. In addition, CFD-simulation is one of the best platforms that provides magnificent understanding development of flow characteristic and particles inside the actuator nozzle. It's also can supply a good indicator of particle flow development with varies color contours. In present study the simulation focus on the orifice diameter only without focusing on others parameter. Therefore, in future work, others parameters such as orifice length and angle can be considered for simulation analysis.

\section{Acknowledgement}

The author would like to acknowledge the Centre of Graduate Studies, Universiti Tun Hussein Onn Malaysia and Postgraduate Research Grant (GPPS) H030 for sponsoring this project.

\section{References}

[1] Smyth, Hugh DC. "The influence of formulation variables on the performance of alternative propellant-driven metered dose inhalers." Advanced Drug Delivery Reviews 55, no. 7 (2003): 807-828.

https://doi.org/10.1016/S0169-409X(03)00079-6

[2] Dolovich, Myrna B., Richard C. Ahrens, Dean R. Hess, Paula Anderson, Rajiv Dhand, Joseph L. Rau, Gerald C. Smaldone, and Gordon Guyatt. "Device selection and outcomes of aerosol therapy: evidence-based guidelines: American College of Chest Physicians/American College of Asthma, Allergy, and Immunology." Chest 127, no. 1 (2005): 335-371.

https://doi.org/10.1378/chest.127.1.335

[3] Haughney, John, David Price, Neil C. Barnes, J. Christian Virchow, and Nicolas Roche. "Choosing inhaler devices for people with asthma: Current knowledge and outstanding research needs." Respiratory Medicine 104, no. 9 (2010): 1237-1245. https://doi.org/10.1016/i.rmed.2010.04.012

[4] Ross, Danna L., and Brian J. Gabrio. "Advances in metered dose inhaler technology with the development of a chlorofluorocarbon-free drug delivery system." Journal of Aerosol Medicine 12, no. 3 (1999): 151-160. https://doi.org/10.1089/jam.1999.12.151

[5] Labiris, N. Renee, and Myrna B. Dolovich. "Pulmonary drug delivery. Part II: the role of inhalant delivery devices and drug formulations in therapeutic effectiveness of aerosolized medications." British Journal of Clinical Pharmacology 56, no. 6 (2003): 600-612. https://doi.org/10.1046/j.1365-2125.2003.01893.x

[6] Dolovich, Myrna B., and Rajiv Dhand. "Aerosol drug delivery: developments in device design and clinical use." The Lancet 377, no. 9770 (2011): 1032-1045. https://doi.org/10.1016/S0140-6736(10)60926-9

[7] Leach, Chet L. "The CFC to HFA transition and its impact on pulmonary drug development." Respiratory Care 50, no. 9 (2005): 1201-1208.

[8] Cheng, Y. S., C. S. Fu, D. Yazzie, and Y. Zhou. "Respiratory deposition patterns of salbutamol pMDI with CFC and HFA-134a formulations in a human airway replica." Journal of Aerosol Medicine 14, no. 2 (2001): 255-266. https://doi.org/10.1089/08942680152484180

[9] Newman, Stephen P. "Principles of metered-dose inhaler design." Respiratory Care 50, no. 9 (2005): 1177-1190.

[10] Crompton, Graham. "A brief history of inhaled asthma therapy over the last fifty years." Primary Care Respiratory Journal 15, no. 6 (2006): 326-331. 
https://doi.org/10.1016/j.pcri.2006.09.002

[11] Stein, Stephen W. "Estimating the Number of Droplets and Drug Particles Emitted from MDIs." AAPS PharmSciTech 9, no. 1 (2008): 112-115. https://doi.org/10.1208/s12249-007-9006-8

[12] Newman, Stephen P., and Michael T. Newhouse. "Effect of add-on devices for aerosol drug delivery: deposition studies and clinical aspects." Journal of Aerosol Medicine 9, no. 1 (1996): 55-70. https://doi.org/10.1089/jam.1996.9.55

[13] Berry, Julianne, Lukeysha C. Kline, Jill K. Sherwood, Saeed Chaudhry, Linda Obenauer-Kutner, John L. Hart, and Joel Sequeira. "Influence of the size of micronized active pharmaceutical ingredient on the aerodynamic particle size and stability of a metered dose inhaler." Drug Development and Industrial Pharmacy 30, no. 7 (2004): 705-714. https://doi.org/10.1081/DDC-120039213

[14] Lewis, D. A., B. J. Meakin, and G. Brambilla. "New actuators versus old: reasons and results for actuator modifications for HFA solution MDIs." Respir Drug Deliv 1 (2006): 101-110.

[15] Sapee, S. "Computational Fluid Dynamics Study on Droplet Size of Kerosene Fuel." Journal of Advanced Research in Fluid Mechanics and Thermal Sciences 16, no. 1 (2015): 1-14.

[16] Stein, Stephen W., Paul B. Myrdal, Brian J. Gabrio, Derek Obereit, and Tyler J. Beck. "Evaluation of a new Aerodynamic Particle Sizer ${ }^{\circledast}$ spectrometer for size distribution measurements of solution metered dose inhalers." Journal of Aerosol Medicine 16, no. 2 (2003): 107-119. https://doi.org/10.1089/089426803321919870

[17] Isa, Kamariah Md, Kahar Osman, Azli Yahya, Zulkifli Abdul Ghaffar, Ahmad Hussein Abdul, and Salmiah Kasolang Hamid. "Studies on the Spray Characteristics of Pressure-Swirl Atomizers for Automatic Hand Sanitizer Application." Journal of Advanced Research in Fluid Mechanics and Thermal Sciences 55, no. 1 (2019): 51-64.

[18] Djupesland, Per Gisle. "Nasal drug delivery devices: characteristics and performance in a clinical perspective-a review." Drug Delivery and Translational Research 3, no. 1 (2013): 42-62.

https://doi.org/10.1007/s13346-012-0108-9

[19] Brambilla, G., T. Church, D. Lewis, and B. Meakin. "Plume temperature emitted from metered dose inhalers." International Journal of Pharmaceutics 405, no. 1-2 (2011): 9-15. https://doi.org/10.1016/i.ijpharm.2010.11.037

[20] Kaur, Ishpreet, Bhumika Aggarwal, and Jaideep Gogtay. "Integration of dose counters in pressurized metered-dose inhalers for patients with asthma and chronic obstructive pulmonary disease: review of evidence." Expert Opinion on Drug Delivery 12, no. 8 (2015): 1301-1310.

https://doi.org/10.1517/17425247.2015.1000858

[21] Oliveira, Ricardo F., S. F. C. F. Teixeira, José C. Teixeira, Luís F. Silva, and Henedina Antunes. "pMDI sprays: Theory, experiment and numerical simulation." Advances in Modeling of Fluid Dynamics (2012): 300.

[22] Dunbar, Craig A., and Anthony J. Hickey. "Evaluation of probability density functions to approximate particle size distributions of representative pharmaceutical aerosols." Journal of Aerosol Science 31, no. 7 (2000): 813-831. https://doi.org/10.1016/S0021-8502(99)00557-1

[23] CLARK, ANDREW R. "MDIs: physics of aerosol formation." Journal of Aerosol Medicine 9, no. s1 (1996): S19-26. https://doi.org/10.1089/jam.1996.9.Suppl_1.S-19

[24] Goswami, Mayank, Sanjeev Kumar, and Prabhat Munshi. "Correlation between numerical simulation and limited data experimental technique for estimation of nitrogen flowing in LMMHD loop." Flow Measurement and Instrumentation 46 (2015): 80-86. https://doi.org/10.1016/i.flowmeasinst.2015.10.002

[25] Oliveira, Ricardo F., Ana C. Ferreira, Senhorinha F. Teixeira, José C. Teixeira, and Helena C. Marques. "pMDI spray plume analysis: a CFD study." In Proceedings of the World Congress on Engineering, vol. 3. 2013. 